\title{
Fake News: Legislation and Judicial Practice
}

\section{凡目 Liudmila Tereschenko}

Associate Professor, Department of Administrative Legislation and Procedure, Institute of Legislation and Comparative Law under the Government of the Russian Federation, Doctor of Juridical Sciences. Address: 34 Bolshaya Cheremushkinskaya Str., Moscow117218, Russian Federation. E-mail: adm2@izak.ru

\section{賟 Abstract}

The article examines relations new to Russian practice regarding the introduction of the concept of "fake news" into the legal field, dissemination of fake news and the problems of legal enforcement of the indicated norms, including administrative and criminal liability.

\section{O-1国 Keywords}

fake news, information security, disinformation, Internet, false information, harmful information, freedom of speech, administrative liability, criminal liability.

For citation: Tereshenko L.K. (2020) Fake New: Legislation and Judicial Practice // Legal Issues in the Digital Age, no 3, pp. 140-147.

DOI: $10.17323 / 2713-2749.2020 .3 .140 .147$

False information has always existed alongside genuine information. The legislator may describe it in differing ways: false information, deceptive information, disinformation, falsified information, but in recent years the term "fake news" appeared at first in literature, then in legislation. It cannot be said that all the abovementioned terms convey an identical meaning, but they do stress the one common characteristic of specific information - its invalidity, inconsistency with reality, and actual state of affairs.

The reasons for the invalidity of information can vary (incorrect selection of the methodology of a study, an inadequate empirical base in scientific and/or sociological studies, deliberate falsification of data, knowing dissemination of false information, etc.) From the legal viewpoint the most interesting and important issues are situations in which the creation and dissemination of false information 
are deliberate and exercise a negative influence on the information security of both individual persons and society as a whole.

State attention to the problem of knowing dissemination of fake information has grown considerably due to the widespread use of the Internet by various social strata, and in the face of the COVID-19 pandemic this problem has increased greatly in importance, and in view of its global nature, governments are striving to find the best way to resolve it ${ }^{1}$.

Knowing fake information may also pursue different aims and be shaped by various purposes, including: concealment of its identity (creation of an account in the name of another person, or a non-existent one) and dissemination of fake information from another's name; increasing the significance of the fake information by claiming expertise in a specific field, creation of tension, public panic, performance of fraud, etc.)

In the conditions of the COVID-19 pandemic, fake information has been employed often in fraudulent activity. For example, internal affairs bodies have been receiving information concerning the sending of fraudulent SMS messages to citizens, demanding payment of fines for alleged breaches of self-isolation, that must be paid immediately2. The term "fake" now refers not just to information, but to sites that are confusingly similar to official sites, to which the recipient is instructed to transfer payment of a fine.

However, the danger of fake information is not limited to fraudulent activities, it extends to fake information regarding the coronavirus infection itself, its spread, methods of countering it and so forth. The Internet contains an enormous body of information about COVID-19, much of it quite contradictory. People are warned about the danger of inoculations that may have a negative effect on their health and even pose a threat to their lives, advising refusal to inoculate; that bodies of state power are allegedly considering forced inoculation, etc. Other information claims

${ }^{1}$ See, for example, Philippines Act of 2017 "On the knowing dissemination of false information and other related illegal offences." False information causing panic, chaos, discord, violence or hatred, as well as information containing elements of propaganda aimed at smearing or discrediting a person; Singapore Act of 2019 "On protection from the Internet dissemination of fake information and manipulations." Establishment of criminal liability for publication of fake news; Germany Act of 2017 Net Enforcement Act (NetzDG). Malaysia Anti-fake News Act of 2018 envisages punishment for initiation of false information and reposting of the same. Fake news are any news, information, communications and reports that are fully or partially false irrespective of format (journalistic or newspaper article, television program, video/audio recording, other format capable of conveying words and thoughts), as well as legal literature: A.D. Scherbakov, Fake news as an object of criminal/ legal regulation: Malaysian experience // Miezhdunarodnoye ugolovnoe parvo i jurisprudentcia. 2018. N 4. P. 18-21 (in Russian); A.N. Ilyashenko. Z.I. Khisamova. Aspects of bringing to book on criminal charges for disseminating fake news in social networks in pandemic conditions // Rossiysky sledovatel. 2020. N 9. P. 12-15 (in Russian)

${ }^{2}$ For greater detail see N.D. Denisov. Negative changes in cybercrimes in the pandemic period and means of countering them // Bezopasnost biznesa. 2020. N 4. P. 37-42 (in Russian) 
that the new coronavirus epidemic is no different from customary influenza, so there is no need to observe the recommended heightened measures of public safety (observing social distancing, use of gloves and face masks, inoculations, etc) ${ }^{3}$. As a result, people are provoked into actions endangering life and health, and hindering the reduction of the coronavirus threat.

A heightened degree of the public danger posed by fake information regarding the new coronavirus infection presupposed the reaction of the state to its dissemination. The Federal Law of 18.03.2019 № 31-FZ “On the introduction of amendments to Article 15.3 of the Federal Law "On information, information technologies and protection of information" established the concept of "false socially significant information", denoting "information disseminated under the guise of reliable communications that pose a threat to the life and (or) health of citizens, property, the threat of mass violations of public order and (or) public safety or the threat of disruption of the functioning or termination of life support facilities, transport or social infrastructure, credit organizations, energy suppliers, business activity or communications."

It is important for law enforcement activity to correlate this determination with a list of socially significant diseases and a list of diseases that endanger the surrounding public. The indicated lists have been affirmed by the Resolution of the Government of the Russian Federation of 1 December 2004 № 715 “On approval of the list of socially significant diseases and list of diseases that pose a danger to others"'. In the new version of this resolution, dated 31 January 2020, the coronavirus infection was included in the list of diseases that pose a threat to the surrounding public.

Simultaneously with the determination of the Federal Law "On information, information technologies and protection of information" the concept of "false socially significant information” was addressed by Federal Law № 27-FZ of 18.03.2019 “On amendments to the Code of Administrative Offences of the Russian Federation"6 (hereinafter - CoAO). Article 13.15 of the $\mathrm{CoAO}$ was augmented by parts 9-11, pursuant to which the dissemination of information endangering the life and health of citizens, property, posing the threat of mass public disorders and threatening the functioning of life support facilities carry the following administrative fines:

for a first offence by private citizens -30 to 100 thousand rubles; for public officials, 60 to 200 thousand rubles; for legal entities, $200-500$ thousand rubles;

${ }^{3}$ See, for example, the Resolution of the Ikryaninsk district court in the Astrakhan region dated 22.06.2020 on case № 5-193/2020.

${ }^{4}$ Rossiyskaya gazeta. 20.03.2019.

5 SZ RF. 2004. № 49. Art. 4916.

6 SZ RF. 2019. № 12. Art. 1217. 
for a repeated offence by private citizens -100 to 300 thousand roubles; for officials, 300 to 600 thousand rubles; for legal entities, 500 thousand to 1 million rubles.

If the dissemination of fake information has caused "a person's death, caused harm to a person's health or property, provoked mass public disorders and (or) endangered public safety, termination of the functioning of life support facilities, threatening transport or social infrastructure, communications, credit organizations, energy supplying objects or business activity", the fines are increased correspondingly:

for private citizens $-300-400$ thousand rubles;

for public officials- $600-900$ thousand rubles;

for legal entities -1 million $-1,5$ million rubles.

The increasing danger to the public caused by fake information in the conditions of the spread of coronavirus infection has indicated the need to introduce not just administrative liability, but criminal liability. In 2020 the Federal Law of 01.04.2020 №100-FZ “On amendments to the Criminal Code of the Russian Federation and Articles 31 and 151 of the Criminal Procedure Code of the Russian Federation"7 introduced criminal liability for the public dissemination of knowingly false information under the guise of reliable information regarding circumstances posing a threat to the life and safety of citizens and (or) measures being enacted to ensure the safety of the population and territories, methods and means of protection against the indicated circumstances (Art. 207.1 of the Russian Criminal Code), and the public dissemination of knowingly false information in the pandemic period (Article 207.2 of the Russian Criminal Code).

Within the short period of the introduction of criminal liability for the public dissemination of knowingly false information it became clear that questions requiring clarification arose in court practice, pursuant to which the Supreme Court of the Russian Federation conducted an amalgamation of separate questions of court practice relating to the application of legislation and means of countering the spread of the new coronavirus infection (COVID-19) on the territory of the Russian Federation, and presented its findings in reviews № 1 and № 2 “Review on selected issues of judicial practice related to the adoption of measures to counter the spread of a new coronavirus infection (COVID-19)" .

One of the main questions at present is the matter of accessibility to justice for private citizens and legal entities in pandemic conditions. In the report presented

7 SZ RF. 2020. № 14 (part I). Art. 2030.

${ }^{8}$ See Review on selected issues of judicial practice related to the adoption of measures to counter the spread of a new coronavirus infection (COVID-19) on the territory of the RF № 2" (approved by the Presidium of the Supreme Court of the RF on 30.04.2020). Available at: URL: https://www. vsrf.ru/files/28856 (accessed: 18.09.2020) 
by Vyacheslav Lebedev, Chairman, Supreme Court of the Russian Federation, at the Forum of chairmen of the supreme courts of BRICS countries "Protection of consumers' rights in contemporary economic conditions", attention of the courts was drawn to the circumstance that the terms for procedural activities missed due to measures for countering the spread of the coronavirus infection (limitation of citizens' freedom of movement, their presence in public places, state or other institutions) are subject to reinstatement in accordance with procedural legislation. The Chairman of the Supreme Court of the Russian Federation noted that the lack of opportunity for a timely approach to a court with a claim is also grounds for the restoration of limitation periods for claims".

As was noted earlier, criminal and administrative liability were introduced regarding fake news. Pursuant to this, a question of principle arose in practice: what criteria differentiate administrative liability for breaches of the law envisaged by parts 9 and 10 of Article 13.15 of the Russian CoAO from criminal liability under Article 207.1 of the Criminal Code in the event of a physical entity disseminating knowingly false information about the new coronavirus infection (COVID-19) in the mass media and information and telecommunication networks under the guise of reliable information? ${ }^{10}$ The difference between illegal actions carrying criminal liability and administrative liability is surely the first question requiring a definitive answer, a mandatory condition for bringing to book, as parts 9 and 10 of Article 13.5 of CoAO indicate that an entity is charged with administrative liability if the actions of the entity disseminating knowingly false information do not contain elements of criminal liability.

Let us compare the norms of Article 207.1 of Criminal Code and parts 9 and 10 of Article 13.5 of CoAO. However, it must be mentioned at the outset that amendments concerning fake information were included in the CoAO article entitled "Abuse of freedom of information", thereby linking it to the mass media.

The Criminal Code established that "The public dissemination of knowingly false information under the guise of reliable information concerning circumstances posing a threat to the life and safety of citizens, and (or) measures employed to ensure the safety of the population and territories, means and methods of protection in the indicated conditions..." Clearly, the Criminal Code contains no indication of the means of the public dissemination of fake information, the main issue being the fact of its public dissemination.

In its Review, the Russian Supreme Court draws attention to the circumstance that within the framework of criminal liability, the public dissemination of knowingly false information may be manifested not only in the use of mass media and information and telecommunication networks, but also in the dissemination of

\footnotetext{
9 SPS Konsultant Plus.

${ }^{10}$ Question 13 of review № 1.
} 
such information by public appearances, meetings, distribution of leaflets, display of posters, etc.

Part 9 of Article 13.5 of CoAO describes the same situation in more detail, and stresses the role of the mass media, and information and telecommunication networks: "The dissemination of knowingly false socially significant information in the mass media under the guise of reliable information, causing a threat of damage to life and (or) health of citizens, property, threat of mass violations of public order and (or) threatening the functioning or termination of life support objects, transport or social infrastructure, credit organizations, energy supplying objects, business activity or communications..." and part 10 of the same article envisages liability for "the dissemination of knowingly false socially significant information in the mass information media and also in information and telecommunication under the guise of reliable information resulting in the creation of obstacles to the functioning of life support objects, transport or social infrastructure, credit organizations, energy supplying objects, business activity or communications. Furthermore, Article 13.15 was later augmented by two more parts: 10.1 and 10.2 concerning the same issues.

The position of the Supreme Court of the Russian Federation in the matter of differentiating criminal and administrative liability comes down to the following. The actions of a physical entity may contain elements of punishable criminality and be qualified under Article 207.1 of the Criminal Code if they occur in the public dissemination of knowingly false information, under the guise of reliable information, concerning circumstances threatening the life and safety of citizens, including circumstances of the spread of the new coronavirus infection (COVID-19) on the territory of the Russian Federation and (or) measures employed to ensure the safety of the population and territories, methods and means of protection in the indicated circumstances, and such dissemination of knowingly false information with consideration of the conditions in which they are performed, the aims and motives behind such actions (for example, provoking public panic, disruption of law and order), pose a genuine public danger and damage relations in the sphere of social security that are protected under criminal law.

Furthermore, the criteria for differentiating between the administrative liability envisaged by parts 10.1 and 10.2 of Article 13.15 of $\mathrm{CoAO}$ and the criminal liability envisaged by articles 207.1 and 207.2 of Criminal Code are viewed by the Supreme Count as subject composition. The Review notes that differentiation must be performed in accordance with the subject of the breach of the law. Administrative liability for actions envisaged by parts 10.1 and 10.2 of Article 13.15 of CoAO concerns only legal entities. Citizens, including public officials, managers of a legal entity may be charged with criminal liability if their actions contain components of a crime covered by Articles 207.1 and 207.2 of the Criminal Code. 
The components under study relevant to the CC RF and CoAO contain categories of evaluation, and also indications of circumstances the content of which is covered by other legislative acts. For instance, the question arises what should be deemed circumstances that pose a threat to the life and security of citizens (art.207.1 of the Criminal Code). The answer to this may be found in the notes to the same article and in a great number of legislative norms concerning emergency situations of a natural or technogenic nature. The notes indicate that circumstances threatening the life and safety of citizens are deemed to be emergency situations of a natural or technogenic nature, ecological emergencies including epidemics, epizootics and other situations caused by accidents, hazardous natural occurrences, catastrophes, natural and other disasters causing (capable of causing) human victims, inflicting damage on people's health and surrounding ecology, significant material losses and disruption of the livelihood of the population. Such a position served as grounds for the Supreme Court of the Russian Federation to relegate the circumstances of the spread of the new coronavirus (COVID-19) infection on the territory of the Russian Federation to circumstances that threaten the life and safety of citizens as indicated in the note to article 207.1 of the Criminal Code of the Russian Federation and clause 2 of notes to article 13.15 of the Code of Administrative Offences of the Russian Federation regarding administrative breaches of the law.

Evaluation categories should include, for example, such terms as "knowingly false information" regarding circumstances that threaten the life and security of citizens", "publicly disseminated information" and "socially significant information." It is very difficult to prove that an individual disseminating a specific piece of information is aware of it being "knowingly false" because he may be sincerely convinced of its objectivity due to the reliability of the source of that information. For such a situation the Russian Supreme Court has established that knowingly false information is deemed to be information (news, communications, data, etc.) that is initially inconsistent with reality, and was known to be so by the disseminator.

There is also a problem with the relegation of publicly disseminated information to the socially significant category. It is not by chance that alongside amendments to the CC RF and CoAO RF, changes were made to Federal Law № 149-FZ of 27 July 2006 "On information, information technologies and protection of information" concerning the nature of socially significant information.

Regarding circumstances threatening the life and safety of citizens, it is important to bear in mind the mention of the coronavirus in an earlier Resolution of the Government of the Russian Federation of 31 January 2020 № 66 stating circumstances of the spread of the new coronavirus infection on the territory of the RF relate directly to circumstances that threaten the life and saafety of citizens. The qualification of actions by a physical entity under art. 207.1 CC RF is also influenced by the aims and motives behind the actions in question. 
In the course of law enforcement procedure there may be a question concerning such a sign as the degree of public nature in the dissemination of information. In the view of the Russian Supreme Court (question 13 in its Review) the knowing dissemination of fake information shall be deemed public if such information is addressed to a group or an unlimited number of persons and is expressed in any form accessible to them. Moreover, it is advisable to take other circumstances into account, including places, method of dissemination (e.g. the mass posting of messages to mobile communication subscribers, use of messaging services such as WhatsApp, Viber and others.

We find it regrettable that practically no use is made of the conceptual framework set out in the Federal Law "On information, information technologies and protection of information" determining actions performed with information. This envisages access to information, provision of information and dissemination of information where access to information is the possibility of receipt of information and its use; provision of information mean actions aimed at the receipt of information by a specific circle of persons or transfer of information to a specific circle of persons; dissemination of information means actions aimed at receipt of information by an indefinite circle of persons or transfer of information to an indefinite circle of persons.

As a result, practically any operations with information are regarded in the Review as its dissemination, even if the information is received by a clearly specified circle of recipients. Consequently, the sending of a message to several of one's friends on WhatsApp shall be seen by the courts as dissemination of information ${ }^{11}$.

In conclusion, we find it necessary to note that the struggle against the coronavirus infection and fake news must not violate the fundamental human right to freedom of speech on one hand, or to soften or revoke the prohibition of censorship, which is guaranteed by the Constitution of the Russian Federation.

${ }^{11}$ See the Resolution of the Buynaksk city court in the republic of Dagestan dated 02.07.2020 on case N 1-110/2020. 